\title{
Lower lip erosion and temporomandibuar joint pain due to the pure mdma intake
}

\begin{abstract}
We described the case of the patient ( 25 years old male) who two nights before coming to the examination to the School of Dentistry, University of Zagreb, took methylenedioxymethamphetamine (MDMA) and presented with symptoms of lower lip bite which resulted in the erosion and temporomandibular joint pain due to the excessive bruxism. The person took 0.25 grams of pure MDMA during that night. The patients were prescribed betamethasone (oitnment) in orabase (powder) (1g: $3 \mathrm{~g}$ mixture) and analgesic (Dexomen, dexketoprofen trometanol, $25 \mathrm{mg}$ three times a day). The lesion and pain subsided after 4 days of the prescribed therapy. It is important that dentists are familiar with oral and dental side-effects of MDMA abuse in order to avoid use of vasoconstrictors and opioids in these patients. Additionally, they might refer these patients for counselling with regard to their bad habit.
\end{abstract}

Volume 2 Issue | - 2018

\author{
Buljubasic R,' Susic M, ${ }^{2}$ Vucicevic Boras V, ${ }^{2}$ \\ Pelivan, ${ }^{1,2}$ Stojic L, ${ }^{2}$ Verzak $Z^{2}$ \\ 'Clinical Hospital Center Dubrava, Croatia \\ ${ }^{2} \mathrm{~S} c h o o l$ of Dentistry, University of Zagreb, Croatia
}

Correspondence: Vucicevic Boras V, School of Dentistry, University of Zagreb, Croatia, Email boras@sfzg.hr

Received: August 19, 2017| Published: January 04, 2018

Keywords: MDMA, serotonergic neurotoxin, psychoactive, drugs, ulcerations

\section{Introduction}

3,4-Methylenedioxymethamphetamine (MDMA) is a serotonergic neurotoxin which has widespread use in drug abusers due to its effect of increased energy level, heightened sense of "closeness" with other people and overall mood enhancement. ${ }^{1}$ MDMA known as ecstasy or molly is a synthetic psychoactive drug with both stimulant and hallucinogenic properties. ${ }^{2}$ It produces an energizing effect, distortions in time and perception, and enhanced enjoyment from sensory experiences. It has also been described as an entactogen-a drug that can increase self-awareness and empathy. ${ }^{3,4}$ MDMA affects dopamine-containing neurons that use chemical serotonin to communicate with other neurons. Subsequently, a decrease in serotonin transporters have been shown in the brain of MDMA users by use of positron emission tomography. ${ }^{2}$ MDMA is usually taken by mouth but it can be also snorted and injected. The effect starts after 20-60 minutes and lasts for 3-6 hours. Physical symptoms of MDMA users are muscle tension, nausea, blurred vision, rapid eye movement, faintness, chills or sweating, raised heart rate and blood pressure and rarely ataxia and seizures while psychological problems manifest in depression anxiety, sleep disturbances, confusion, agitation and even paranoia. ${ }^{2}$ Patients attending dental office who intake MDMA usually present with poor oral hygiene, xerostomia, rampant caries i.e. "methmouth" and excessive tooth wear. ${ }^{5}$ Furthermore, it has been reported that MDMA abusers are prone to bruxism, TMJ dysfunction, mucosal burns and ulcerations and periodontitis. ${ }^{2}$

\section{Case report}

We describe case of the patient (25 years old male) who two nights before coming to the examination to the School of Dentistry, University of Zagreb, took methylenedioxymethamphetamine (MDMA) and presented with symptoms of lower lip bite which resulted in erosion (Figure 1) and temporomandibular joint pain due to the excessive bruxism. The person took 0.25 grams of pure MDMA during that night. The patients was prescribed betamethasone (ointment) in orabase (powder) (1g: $3 \mathrm{~g}$ mixture) and analgesic (Dexomen, dexketoprofen trometanol, $25 \mathrm{mg}$ three times a day). The lesion and pain subsided after 4 days.

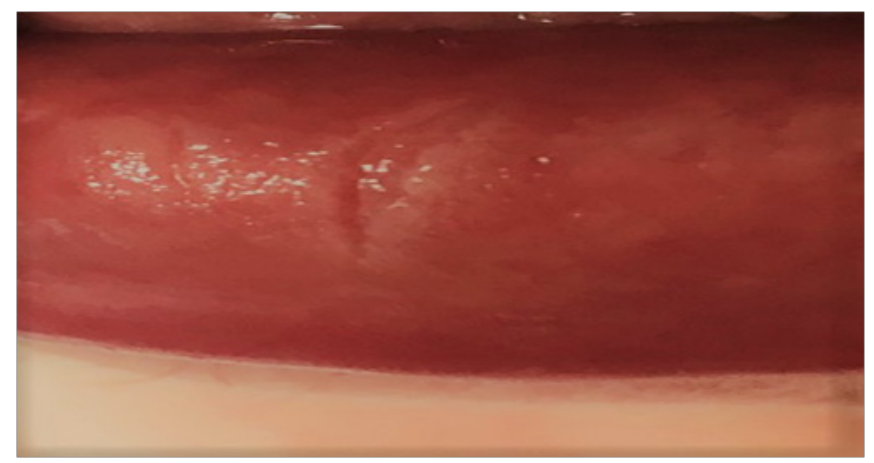

Figure I Lower lip erosion due to the MDMA intake.

\section{Discussion}

Probably due to the amphetamine-like properties of MDMA, i.e. sympathomimetic properties, the most frequent side effects are xerostomia, bruxism and/or trismus in the oral cavity. Furthermore, Rhodus et $a .^{6}$ reported that enamel erosion and rampant caries are frequent in those patients. Brand et al. ${ }^{7}$ reported that mucosal alterations are frequent in these patients. Baylen et al..$^{8}$ summarized changes from 24 studies upon MDMA abusers which were either emotional (e.g. anxiety, depression, closeness, fear, euphoria, calmness) or somatic (e.g. nausea/vomiting, bruxism, muscle aches/ headache, sweating, numbness, body temperature changes, fatigue, dizziness, dry mouth, increased energy). Ahmed et al. ${ }^{9}$ reported widespread oral and oropharyngeal mucosal oedema, which started after ecstasy and alcohol were taken by the patient and what was almost fatal in this patient.

Milosevic et al. ${ }^{10}$ reported that tooth-wear through the enamel into the underlying dentine occurred in $18(60 \%)$ ecstasy users, xerostomia occurred in $93 \%$ of ecstasy users and $89 \%$ reported that they clenched or ground their teeth after taking the drug. Furthermore, Milosevic et al. ${ }^{10}$ concluded that the occlusal surfaces were more commonly affected than the incisal, which may indicate jaw clenching rather than grinding as a result of ecstasy-separate induced muscle hyperactivity. 
This finding was also seen in our patient. McGrath et al. ${ }^{11}$ found out that the most frequently dry mouth $(95 \%)$ as well as chewing, grinding and TMJ tenderness. Nixon et al. ${ }^{12}$ concluded that the regular use of amphetamine-like drugs could be associated with increased posterior tooth wear (especially of the lower first molar teeth). A rare case of almost fatal angioedema due to the MDMA intake was also described in the literature. ${ }^{13}$ Naidoo \& Smit ${ }^{5}$ described a case of 24 year old man with severe dental pain, halitosis and self-reported poor dental appearance as a result of methamphetamine. The same findings were reported by Turkyilmaz ${ }^{14}$ in a 30 year old female. As the number of patients abusing methamphetamines is increasing, every dentist must be familiar with clinical oral, dental and temporomandibular joint presentations of MDMA abusers. Furthermore, it should be highlighted that use of amphetamines increase the symphatomimetic effects of epinephrine therefore vasoconstrictors should be avoided as hypertension and cardiotoxicity might develop. Additionally, use of opioids in MDMA abusers should be avoided.

\section{Acknowledgements}

None.

\section{Conflict of interest}

The author declares no conflict of interest.

\section{References}

1. Peroutka SJ, Newman H, Harris H. Subjective effects of 3,4methylenedioxymethamphetamine in recreational users. Neuropsychopharmacology. 1988;1(4):273-277.

2. Scully C, Diz Dios P, Kumar N. Special care in dentistry. UK: Churchill Livingstone; 2006. p. 42-45.
3. Hermle L, Spitzer M, Borchardt D, et al. Psychological effects of MDE in normal subjects. Are entactogens a new class of psychoactive agents? Neuropsychopharmacology. 1993;8(2):171-176.

4. Vollenweider FX. Brain mechanisms of hallucinogens and entactogens. Dialogues Clin Neurosci. 2001;3(4):265-279.

5. Naidoo S, Smit D. Methamphetamine abuse: a review of the literature and case report in a young male. SADJ. 2011;66(3):124-127.

6. Rhodus NL, Little JW. Methamphetamine abuse and "meth mouth". Northwest Dent. 2005;84(5):29,31,33-37.

7. Brand HS, Dun SN, van Nieuw Amerongen A. Ecstasy use and oral health. Ned Tijdschr Tandheelkd. 2007;114(2):104-108.

8. Baylen CA, Rosenberg H. A review of the acute subjective effects of MDMA/ecstasy. Addiction. 2006;101(7):933-947.

9. Ahmed M, Islam S, Hoffman GR. Widespread oral and oropharyngeal mucosal oedema induced by ecstasy (MDMA): A case for concern. Br J Oral Maxillofac Surg. 2007;45(6):496-498.

10. Milosevic A, Agrawal N, Redfearn P, et al. The occurrence of tooth-wear in users of Ecstasy (3,4-methylenedioxymethamphetamine). Community Dent Oral Epidemiol. 1999;27(4):283-287.

11. McGrath $\mathrm{C}$, Chan B. Oral health sensations associated with illicit drug abuse. Br Dent J. 2005;198(3):159-162.

12. Nixon PJ, Youngson CC, Beese A. Tooth surface loss: does recreational drug use contribute? Clin Oral Investig. 2002;6(2):128-130.

13. Crampsey DP, Little SA. Uvula angio-oedema: ENT form of Saturday night palsy. BMJ. 2007;335(7615):318.

14. Turkylmaz I. Oral manifestations of meth mouth: a case report. J Contem Dent Pract. 2010;11(1):E073-E080. 